\title{
The endothelial cell markers von Willebrand Factor (vWF), CD31 and CD34 are lost in glomerulonephritis and no longer correlate with the morphological indices of glomerular sclerosis, interstitial fibrosis, activity and chronicity
}

\author{
Cristina Gluhovschi'1, Gheorghe Gluhovschi1, Elena Potencz ${ }^{2}$, Diana Herman², \\ Virginia Trandafirescu ${ }^{1}$, Ligia Petrica ${ }^{1}$, Silvia Velciov ${ }^{1}$, Gheorghe Bozdog${ }^{1}$, \\ Flaviu Bob ${ }^{1}$, Corina Vernic ${ }^{3}$, Daniel Cioca ${ }^{4}$
}

${ }^{1}$ Division of Nephrology, University of Medicine and Pharmacy "V. Babes" Timisoara, Romania

2Division of Pathology, University of Medicine and Pharmacy "V. Babes" Timisoara, Romania

${ }^{3}$ Department of Medical Informatics and Biostatistics, University of Medicine and Pharmacy "V. Babes"

Timisoara, Romania

${ }^{4}$ Department of Cellular and Molecular Biology, University of Medicine and Pharmacy "V. Babes"

Timisoara, Romania

\begin{abstract}
Endothelial cells (ECs) are active participants of an inflammatory process in glomeruli. EC damage has been shown to play an important role in the progression of glomerulonephritis (GN). The degree of glomerular and peritubular capillary loss in models of progressive renal disease correlates with the severity of glomerulosclerosis and interstitial fibrosis. The aim of our study was to analyze the association of vWF, CD31 and CD34 immunoreactivity with the morphological indices of glomerular sclerosis, interstitial fibrosis, activity and chronicity in GN. A cross-sectional study of 22 patients with GN was conducted. Conventional stains (hematoxylin-eosin, periodic acid Schiff and Trichrome Gömöri stains) and immunohistochemistry (vWF, CD31 and CD34) were employed on kidney biopsies. Activity and chronicity of GN, as well as glomerular segmental sclerosis and interstitial fibrosis, were evaluated according to a scoring system initially used for lupus nephritis and antineutrophil-cytoplasmic-antibody-associated vasculitis. Immunohistochemistry was assessed using a semi-quantitative score. Statistical analysis was performed using EpiInfo 6.04. The mean patient age was $46.68 \pm 14.09 ; 14$ patients were male, and eight were female. Performing Spearman`s rank correlation test, no correlation was found between each marker and glomerular segmental sclerosis, interstitial fibrosis, activity and chronicity, which suggests a loss of these markers and microvasculature involvement.
\end{abstract}

Key words: glomerular disease, vWF, CD31, CD34

\section{Introduction}

Endothelial cells (ECs) are strategically located at the interface between circulating blood elements and tissues. The endothelium has multiple, diverse functions,

Correspondence: C. Gluhovschi, Division of Nephrology, University of Medicine and Pharmacy "V. Babes", Calea Aradului No. 8 Ap.16, 300088 Timisoara Romania; tel.: (+40256) 435950, e-mail: gluhovschi@yahoo.com, gluh@umft.ro ranging from control of vasomotor tone to hemostasis. It secretes a wide spectrum of molecules into the blood and the subendothelial matrix. These molecules are involved in the formation of platelet and fibrin thrombi (e.g., von Willebrand Factor (vWF) and tissue factors), contribute to the antithrombotic properties of the endothelium (e.g., prostacyclin, thrombomodulin and heparan sulfate), express plasminogen activators and inhibitors, regulate the growth of other cells, bind lipoproteins and hormones, and are involved in immune reactions $[1,2]$. 
Progressive renal disease is characterized by a progressive loss of the microvasculature, which correlates directly with the development of glomerular and tubulointerstitial scarring. This mechanism is mediated, in part, by a reduction in the endothelial proliferative response [3].

Morphometric studies have documented that the initial response to a decrease in nephron number is a hypertrophic response in which glomerular capillaries increase in both number and length [4,5]. Shimizu [6] and Kitamura [7] have also shown an early proliferative response of the glomerular endothelium in rats with either anti-GBM disease or with remnant kidneys, respectively [6,7]. Unfortunately, the proliferation is not sustained, and there is a progressive loss of the endothelium due to unchecked apoptosis over time [3]. They posit that the loss of the glomerular endothelium predisposes to activation of platelets and the coagulation system that favors capillary collapse and the development of glomerulosclerosis [3]. Indeed, the loss of glomerular endothelium correlates directly with the development of glomerulosclerosis $[6,7]$.

A similar phenomenon also occurs in the interstitium. Bohle and Choi $[8,9]$ demonstrated that peritubular capillary loss is correlated with interstitial fibrosis and tubular atrophy, independent of the injury to larger blood vessels $[8,9]$.

Under pathological conditions, ECs may be lost, or they can modify their antigen expression pattern [10]. Three of the markers for ECs are vWF, CD31 and CD34.

vWF is a large glycoprotein with a multimeric structure and a molecular mass ranging from $500 \mathrm{kDa}$ up to more than $10000 \mathrm{kDa}$, the latter being the largest known for a soluble plasma protein. vWF is present in plasma, in the Weibel-Palade bodies of endothelial cells, in the alpha-granules in megakaryocytes and platelets derived from them, as well as in the subendothelial matrix of the vessel wall. vWF mediates platelet adhesion and thrombus formation at sites of vascular injury and serves as a carrier for factor VIII in plasma, protecting the circulating coagulation enzyme from proteolytic degradation [11].

The $130 \mathrm{kDa}$ transmembrane glycoprotein platelet endothelial cell adhesion molecule (PECAM-1 or CD31) of the immunoglobulin (Ig) superfamily is expressed on the surface of circulating platelets, monocytes, neutrophils and selected T-cell subsets and is a constituent of the endothelial intercellular junction. PECAM-1 is found in large amounts on ECs, but is less abundant on platelets and most leukocytes. It plays a major role in a number of cellular interactions, most notably in the adhesion cascade between ECs and polymorphonuclear leukocytes, monocytes and lymphocytes (by heterophilic cell interactions) in inflammatory processes and between adjacent ECs (by homophilic cell interactions) during the process of angiogenesis $[1,12,13]$. It also appears to be required for neutrophil transmigration [1].

CD34, regarded as a common diagnostic EC marker, is a $105-120 \mathrm{kDa}$ transmembrane glycoprotein, present on lymphohematopoietic stem and progenitor cells, leukemic cells, ECs and fibroblasts. CD34 is a stage-specific, rather than a lineage-specific, leukocyte differentiation antigen. CD34 expression patterns during development appear to be related to modes of blood vessel formation and reveal additional sites of hematopoiesis [14]. Less is known about the significance and modulation of endothelial CD34 expression [1].

We used vWF, CD31 and CD34 as immunohistochemical markers of ECs.

The aim of our study was to analyze the association of vWF, CD31 and CD34 immunoreactivity with the morphological indices of glomerular sclerosis, interstitial fibrosis, activity (AI) and chronicity (CI) in glomerulonephritis (GN).

\section{Materials and methods}

Subjects. A cross-sectional study of 22 patients with GN (mean age: $46.68 \pm 14.09$; 14 male, and 8 female), hospitalized in the Division of Nephrology, University of Medicine and Pharmacy "V. Babes" Timisoara, Romania during 2006, was performed.

All patients underwent a thorough clinical examination (history and physical exam), diagnostic procedures (chest X-rays, electrocardiogram and abdominal ultrasound) and standard laboratory evaluation (complete blood count, erythrocyte sedimentation rate, fasting glucose levels, serum urea, serum creatinine, lipid profile, total serum protein levels with electrophoresis, liver enzymes, urinalysis, urinary protein excretion and urine cultures) for their underlying disease. Patient examination was extended for diagnostic purposes and associated comorbidities on a case-by-case basis. Every attempt was made to rule out secondary disease (malignancy, infection or autoimmune disease) by ordering antinuclear antibodies, extractable nuclear antigen profile, lupus erythematosus cells, antineutrophil cytoplasmic antibodies (ANCAs; enzymelinked immunosorbent assay and/or indirect immunofluorescence), C3, serum immunoglobulin levels, rheumatoid factor, Bence Jones protein, and cryoglobulin test. All patients underwent percutaneous kidney biopsies after providing informed consent.

Histology. Routinely fixed and processed kidney sections were processed for light microscopy and stained with hematoxylineosin, periodic acid Schiff and Gömöri`s trichrome technique, using routine methods.

Kidney biopsy evaluation. All biopsy specimens were assessed by two pathologists. Activity was expressed by the activity index (AI), and chronicity was expressed by the chronicity index (CI). Each index was gauged according to a scoring system proposed by Neumann and coworkers [15] for ANCA-associated vasculitis based on the standardized scoring system for activity and chronicity developed for lupus nephritis. According to this scoring system, the glomeruli, tubuli and vessels were independently assessed for inflammatory (active) and sclerotic-fibrotic (chronic) lesions.

The glomeruli were divided into eight segments, and each segment was evaluated for mesangial cell proliferation, intracapillary proliferation-infiltration, fibrinoid necrosis, extracapillary 
proliferation, mesangial matrix increase, segmental sclerosis and fibrosed crescents-adhesions. The number of affected segments (a) was employed to compute the percentage of glomeruli affected by each of the changes, by using either the formula:

a $\times 12.5 / n$,

where $\mathrm{a}=$ the number of affected segments and $\mathrm{n}=$ the number of glomeruli, for assessing mesangial cell proliferation, fibrinoid necrosis and mesangial matrix increase, or

$(m \times 8+a) \times 100 / n \times 8$,

where $\mathrm{m}=$ the number of glomerular scars for the evaluation of segmental sclerosis.

Points were attributed as follows: 1 point was given for less than 20\% involvement; 2 points for an involvement between 21 $40 \%$; 3 points for $41-60 \%$ involvement; 4 points for $61-80 \%$ involvement; and 5 points for $81-100 \%$ involvement.

At the tubulointerstitial level, inflammatory lesions (edema and interstitial infiltrate), and sclerotic-fibrotic lesions (interstitial fibrosis, tubular atrophy and vascular hyalinosis-fibrosis) were assessed.

To evaluate the tubulointerstitial lesions, a semi-quantitative scoring system was used as follows: 1 point was attributed for an involvement of less than $30 \%$ (mild) of the tubules or the interstitial area; 2 points for involvement between 31-60\% (moderate); and 3 points for involvement in the $61-100 \%$ range (severe). Results were used to compute the AI and the CI.

Immunohistochemistry was graded for statistical evaluation using a semi-quantitative intensity scale from 0 to 3 (absent, mild, moderate and intense).

Only sections containing more than six glomeruli, estimated as optimal [16], were considered.

Immunohistochemistry. The detection of vWF, CD31 and CD34 was performed on $6-\mu \mathrm{m}$ thick, routinely formalin-fixed, paraffinembedded sections using the horseradish-peroxidase labeled streptavidin-biotin (LSAB2-HRP) method. The primary antibodies used were monoclonal mouse anti-vWF (Clone F8/86, DAKO), monoclonal mouse anti-CD31 (Clone JC70A, DAKO) and monoclonal mouse anti-CD34 Class II (Clone QBEnd 10, 581, DAKO). The LSAB2-HRP technique was employed as specified by the manufacturer's protocol. Briefly, sections were deparaffinized, rehydrated with distilled water and pretreated with Tris-ethylenediaminetetraacetic acid buffer ( $\mathrm{pH} 9.0)$ until the temperature reached $95^{\circ} \mathrm{C}$. The next step was serum blocking followed by incubation with the primary antibodies, diluted 1:50. Following peroxidase blocking, sections were sequentially incubated with a biotinylated secondary antibody and peroxidase-labeled streptavidin. Labeling was completed by incubating the sections with the chromogenic substrate solution 3,3'-diaminobenzidine (DAB). Finally, sections were counterstained with Mayer's hematoxylin, rinsed in running tap water, and dehydrated. Sections were then cleared in two changes of toluene and mounted using Eukit.

Normal-appearing tissue from three patients who underwent nephrectomy for suspected kidney tumors was used as a control.

Statistical analysis. Statistical analysis was performed using the EpiInfo 6.04, Epi 3.2.2. and SPSS 10 packages and consisted of computing the frequency counts as well as percentages for the qualitative variables, the means, medians and standard deviations for the quantitative variables and Spearman's rank correlation coefficient. We used Colton`s [17] interpretation of Spearman`s rank correlation coefficient as follows:

$0-0.25$, little or no correlation;

$0.25-0.5$, fair degree of relationship;

$0.5-0.75$, moderate to good correlation; and

$0.75-1$, very good to excellent correlation.

Statistical significance was considered as $\mathrm{p}<0.05$.

\section{Results}

The 22 patients presented the following histopathological forms of GN:

- 3 patients: crescentic GN (2 primary, 1 vasculitis);

- 8 patients: focal and segmental glomerulosclerosis (FSGS) (all primary);

- 6 patients: mesangial proliferative GN (all primary);

- 3 patients: membranous nephropathy (MN) (all primary);

- 1 patient: minimal change disease (MCD) (primary); and

- 1 patient: membranoproliferative GN (lymphoma).

Overall, across all 22 patients:

- Mesangial cell proliferation expressed as a percentage was $37.19 \pm 36.2$;

- The mesangial cell proliferation score was $2.23 \pm 1.88$;

- The AI was $8.68 \pm 5.9$;

- The mesangial matrix increase score was $1.82 \pm 1.4$;

- The glomerular segmental sclerosis score was $1.68 \pm 1.36$;

- The interstitial fibrosis score was $1.77 \pm 0.87$;

- The tubular atrophy score was $1.5 \pm 0.86$;

- The CI was $9.82 \pm 4.7$;

- CD34 immunoexpression at the level of the glomerular endothelium was $2.36 \pm 0.73$;

- CD34 immunoexpression at the level of the interstitial vessels was $2.19 \pm 0.68$;

- CD31 immunoexpression at the level of the glomerular endothelium was $1.55 \pm 0.51$;

- CD31 immunoexpression at the level of the interstitial vessels was $1.32 \pm 0.58$;

- vWF immunoexpression at the level of the glomerular endothelium was $1.14 \pm 0.35$; and

- vWF immunoexpression at the level of the interstitial vessels was $1.14 \pm 0.36$.

The values of the main histological parameters for inflammatory (active) lesions, mesangial cell proliferation (expressed both as a percentage and as an absolute score) and AI (detailed for each histopathological form of GN), are presented in Table 1.

The values of the main histological parameters for sclerotic-fibrotic (chronic) lesions, mesangial matrix increase score, glomerular segmental sclerosis score, interstitial fibrosis score, tubular atrophy score and CI (detailed for each histopathological form of GN) are presented in Table 2.

The values of the immunohistochemical parameters vWF, CD31 and CD34, at the level of both the glomerular endothelium and the interstitial vessels (detailed for each histopathological form of GN), are shown in Table 3.

We performed Spearman's rank correlation test between the immunohistochemical markers (vWF, 
Table 1. Values of the main histological parameters for inflammatory (active) lesions detailed for each histopathological form of GN.

\begin{tabular}{|l|c|c|c|c|}
\hline \multicolumn{1}{|c|}{ Histopathological form } & Number of patients & Mesangial cell proliferation (\%) & $\begin{array}{c}\text { Mesangial cell proliferation } \\
\text { score }\end{array}$ & $\begin{array}{c}\text { Activity } \\
\text { Index }\end{array}$ \\
\hline Crescentic GN & 3 & $36.38 \perp 23.35$ & $2.33 \pm 1.53$ & $18 \perp 2$ \\
\hline FSGS & 8 & $15.07+17.25$ & $1.25+1.04$ & $7.75+3.54$ \\
\hline Mesangial proliferative GN & 6 & $81.27 \pm 16.7$ & $4.33 \pm 0.82$ & $9.17 \pm 4.49$ \\
\hline Membranous nephropathy & 3 & 0 & 0 & $1.33 \pm 1.53$ \\
\hline Minimal change disease & 1 & 12.5 & 1 & 1 \\
\hline Membranoproliferative GN & 1 & 88.33 & 5 & 15 \\
\hline
\end{tabular}

Table 2. Values of the main histological parameters for sclerotic-fibrotic (chronic) lesions detailed for each histopathological form of GN.

\begin{tabular}{|l|c|c|c|c|c|c|}
\hline \multicolumn{1}{|c|}{ Histopathological form } & $\begin{array}{c}\text { Number of } \\
\text { paticnts }\end{array}$ & $\begin{array}{c}\text { Mesangial } \\
\text { matrix increase } \\
\text { score }\end{array}$ & $\begin{array}{c}\text { Glomerular } \\
\text { segmental } \\
\text { sclerosis score }\end{array}$ & $\begin{array}{c}\text { Interstitial } \\
\text { fibrosis scorc }\end{array}$ & $\begin{array}{c}\text { Tubular } \\
\text { atrophy score }\end{array}$ & $\begin{array}{c}\text { Chronicity } \\
\text { Index }\end{array}$ \\
\hline Crescentic GN & 3 & $3+2$ & $1.67+1.15$ & $2.33+0.58$ & 2 & $13.33+2.52$ \\
\hline FSGS & 8 & $1.13+0.64$ & $2.88+1.25$ & $2.25+0.46$ & $2.13+0.64$ & $12.38+2.67$ \\
\hline Mesangial proliferative GN & 6 & $2.5+1.38$ & $1+0.89$ & $1.5+0.84$ & $1.17+0.75$ & $8.83+4.36$ \\
\hline Membranous nephropathy & 3 & $0.67 \pm 0.58$ & $0.33 \pm 0.58$ & $0.67 \pm 1.15$ & $0.33 \pm 0.58$ & $2.67 \pm 3.06$ \\
\hline Minimal change disease & 1 & 1 & 1 & 1 & 1 & 4 \\
\hline Membranoproliferative GN & 1 & 4 & 1 & 2 & 1 & 12 \\
\hline
\end{tabular}

Table 3. Values of the immunohistochemical parameters vWF, CD31 and CD34 detailed for each histopathological form of GN.

\begin{tabular}{|l|c|c|c|c|c|c|c|}
\hline \multicolumn{1}{|c|}{ Histopathological form } & $\begin{array}{c}\text { Number } \\
\text { of } \\
\text { patients }\end{array}$ & $\begin{array}{c}\text { CD34 } \\
\text { glomerular } \\
\text { endothelium }\end{array}$ & $\begin{array}{c}\text { CD34 } \\
\text { interstitial } \\
\text { vessels }\end{array}$ & $\begin{array}{c}\text { CD31 } \\
\text { glomerular } \\
\text { endothelium }\end{array}$ & $\begin{array}{c}\text { CD31 } \\
\text { interstitial } \\
\text { vessels }\end{array}$ & $\begin{array}{c}\text { vWF } \\
\text { glomerular } \\
\text { endothelium }\end{array}$ & $\begin{array}{c}\text { vWF } \\
\text { interstitial } \\
\text { vessels }\end{array}$ \\
\hline Crescentic GN & 3 & 3 & 3 & $1.67 \pm 0.58$ & $1.33 \pm 0.58$ & $1.33 \pm 0.58$ & $1.33 \pm 0.58$ \\
\hline FSGS & 8 & $2.5 \pm 0.76$ & $2.13 \pm 0.64$ & $1.5 \pm 0.53$ & $1.43 \pm 0.53$ & $1.13 \pm 0.35$ & 1 \\
\hline Mesangial proliferative GN & 6 & $2 \pm 0.89$ & $2 \pm 0.71$ & $1.5 \pm 0.55$ & 1 & 1 & $1.2 \pm 0.45$ \\
\hline Membranous nephropathy & 3 & $2.33 \pm 0.58$ & $2.33 \pm 0.58$ & $1.67 \pm 0.58$ & $1.67 \pm 0.58$ & $1.33 \pm 0.58$ & $1.33 \pm 0.58$ \\
\hline Minimal change disease & 1 & 2 & 2 & 1 & 0 & 1 & 1 \\
\hline Membranoproliferative GN & 1 & 2 & 1 & 2 & 2 & 1 & 1 \\
\hline
\end{tabular}

CD31 and CD34) and glomerular segmental sclerosis, interstitial fibrosis, AI and CI across all 22 patients. The relationships between these parameters are shown in Tables 4 to 7 .

An example of the immunohistochemical localization of CD34, CD31 and vWF is shown in Fig. 1-3, respectively.

\section{Discussion}

The classic paradigm for the pathogenesis of progressive renal disease postulates that homeostatic mechanisms involved in maintaining the glomerular filtration rate (GFR) in the setting of reduced nephron number dilate the afferent arteriole and constrict the efferent arteriole [18]. The resultant increase in systemic and glomerular hydrostatic pressure causes glomerular endothelial injury [19].

Injury of the glomerular capillary network with endothelial cell damage has been shown to play an important role in the progression of GN [20]. During the progression of $\mathrm{GN}$, a loss of glomerular and peritubular microvasculature has been described [3]. The degree of glomerular and peritubular capillary loss in models of progressive renal disease correlates with the severity of glomerulosclerosis and interstitial fibrosis [3]. According to Kitamura [7], this is in relationship to EC apoptosis and to the development of glomerulosclerosis [7]. 
Table 4. Relationship between CD34, CD31 and vWF immunoexpression and glomerular segmental sclerosis.

\begin{tabular}{|l|c|c|}
\hline \multicolumn{1}{|c|}{ Parameter } & \multicolumn{1}{|c|}{$\begin{array}{c}\text { Correlation } \\
\text { coefficient }\end{array}$} & $\mathrm{p}$-value \\
\hline $\begin{array}{l}\text { CD34 glomerular } \\
\text { endothelium }\end{array}$ & $\mathrm{r}=0.267$ & $\mathrm{p}=0.229$ \\
\hline CD34 interstitial vessels & $\mathrm{r}=0.008$ & $\mathrm{p}=0.974$ \\
\hline $\begin{array}{l}\text { CD31 glomerular } \\
\text { endothelium }\end{array}$ & $\mathrm{r}=-0.219$ & $\mathrm{p}=0.328$ \\
\hline CD31 interstitial vessels & $\mathrm{r}=-0.004$ & $\mathrm{p}=0.988$ \\
\hline $\begin{array}{l}\text { vWF glomerular } \\
\text { endothelium }\end{array}$ & $\mathrm{r}=-0.104$ & $\mathrm{p}=0.644$ \\
\hline vWF interstitial vessels & $\mathrm{r}=-0.134$ & $\mathrm{p}=0.563$ \\
\hline
\end{tabular}

Table 6. Relationship between CD34, CD31 and vWF immunoexpression and the Activity Index.

\begin{tabular}{|l|c|c|}
\hline \multicolumn{1}{|c|}{ Parameter } & $\begin{array}{c}\text { Correlation } \\
\text { coefficient }\end{array}$ & $\mathrm{p}$-value \\
\hline $\begin{array}{l}\text { CD34 glomerular } \\
\text { endothelium }\end{array}$ & $\mathrm{r}=0.028$ & $\mathrm{p}=0.901$ \\
\hline CD34 interstitial vessels & $\mathrm{r}=0.026$ & $\mathrm{p}=0.911$ \\
\hline $\begin{array}{l}\text { CD31 glomerular } \\
\text { endothelium }\end{array}$ & $\mathrm{r}=-0.066$ & $\mathrm{p}=0.77$ \\
\hline CD31 interstitial vessels & $\mathrm{r}=0.006$ & $\mathrm{p}=0.981$ \\
\hline $\begin{array}{l}\text { vWF glomerular } \\
\text { endothelium }\end{array}$ & $\mathrm{r}=0.022$ & $\mathrm{p}=0.923$ \\
\hline vWF interstitial vesscls & $\mathrm{r}=0.023$ & $\mathrm{p}=0.921$ \\
\hline
\end{tabular}

Similarly, Ohashi [21] demonstrates that EC apoptosis correlates with peritubular capillary loss, which is associated with tubulointerstitial fibrosis and tubular atrophy [21]. Transforming growth factor- beta (TGF-beta) could be a contributor to capillary EC loss [22].

Conversely, reversal of glomerular lesions involves the coordinated restructuring of the glomerular microvasculature [23].

This cross-sectional study sought to analyze the association of immunoreactivity for vWF, CD31 and CD34 with the morphological indices of glomerular sclerosis, interstitial fibrosis, $\mathrm{AI}$ and $\mathrm{CI}$ in GN. To better quantify the histological lesions, a scoring system adapted from Neumann [15] was employed on kidney biopsies. We used this scoring system in two previous reports $[24,25]$.

Patients with crescentic GN showed the highest AI $(18 \pm 2)$ and also the highest CI $(13.33 \pm 2.52)$.

Furthermore, the patient with membranoproliferative GN showed an AI of 15 and a CI of 12 .

As expected, patients with mesangial proliferative GN and the patient with membranoproliferative GN
Table 5. Relationship between CD34, CD31 and vWF immunoexpression and interstitial fibrosis.

\begin{tabular}{|l|c|c|}
\hline \multicolumn{1}{|c|}{ Parameter } & \multicolumn{1}{|c|}{$\begin{array}{c}\text { Correlation } \\
\text { coefficient }\end{array}$} & $\mathrm{p}$-value \\
\hline $\begin{array}{l}\text { CD34 glomerular } \\
\text { endothelium }\end{array}$ & $\mathrm{r}=0.288$ & $\mathrm{p}=0.194$ \\
\hline CD34 interstitial vessels & $\mathrm{r}=0.162$ & $\mathrm{p}=0.484$ \\
\hline $\begin{array}{l}\text { CD31 glomerular } \\
\text { endothelium }\end{array}$ & $\mathrm{r}=0.078$ & $\mathrm{p}=0.729$ \\
\hline CD31 interstitial vessels & $\mathrm{r}=0.264$ & $\mathrm{p}=0.276$ \\
\hline $\begin{array}{l}\text { vWF glomerular } \\
\text { cndothelium }\end{array}$ & $\mathrm{r}=-0.05$ & $\mathrm{p}=0.826$ \\
\hline vWF interstitial vessels & $\mathrm{r}=-0.202$ & $\mathrm{p}=0.381$ \\
\hline
\end{tabular}

Table 7. Relationship between CD34, CD31 and vWF immunoexpression and the Chronicity Index.

\begin{tabular}{|l|c|c|}
\hline \multicolumn{1}{|c|}{ Parameter } & $\begin{array}{c}\text { Correlation } \\
\text { coefficient }\end{array}$ & $\mathrm{p}$-value \\
\hline $\begin{array}{l}\text { CD34 glomerular } \\
\text { endothelium }\end{array}$ & $\mathrm{r}=0.216$ & $\mathrm{p}=0.335$ \\
\hline CD34 interstitial vessels & $\mathrm{r}=0.073$ & $\mathrm{p}=0.754$ \\
\hline $\begin{array}{l}\text { CD31 glomerular } \\
\text { endothelium }\end{array}$ & $\mathrm{r}=-0.076$ & $\mathrm{p}=0.737$ \\
\hline CD31 interstitial vessels & $\mathrm{r}=0.2$ & $\mathrm{p}=0.412$ \\
\hline $\begin{array}{l}\text { vWF glomerular } \\
\text { endothelium }\end{array}$ & $\mathrm{r}=0.016$ & $\mathrm{p}=0.945$ \\
\hline vWF interstitial vessels & $\mathrm{r}=-0.037$ & $\mathrm{p}=0.872$ \\
\hline
\end{tabular}

showed increased mesangial cell proliferation (when expressed both as a percentage and as an absolute score): $81.27 \pm 16.7$ (mesangial cell proliferation percentage for the patients with mesangial proliferative GN), $4.33 \pm 0.82$ (mesangial cell proliferation score for the patients with mesangial proliferative GN), 88.33 (mesangial cell proliferation percentage for the patient with membranoproliferative GN) and 5 (mesangial cell proliferation score for the patient with membranoproliferative GN), respectively.

Patients with FSGS had a glomerular segmental sclerosis score of $2.88 \pm 1.25$, which was the highest score of glomerular segmental sclerosis among the different histopathological forms of GN. Patients with FSGS had a CI of $12.38 \pm 2.67$.

Glomerular and tubulointerstitial scarring are universal outcomes of renal disease progression. Chronic progressive kidney disease in humans frequently is a protracted, focal and/or segmental process, progressive renal disease being characterized in part by a progressive loss of the glomerular and peritubular microvasculature [3,22]. Additionally, segmental loss 


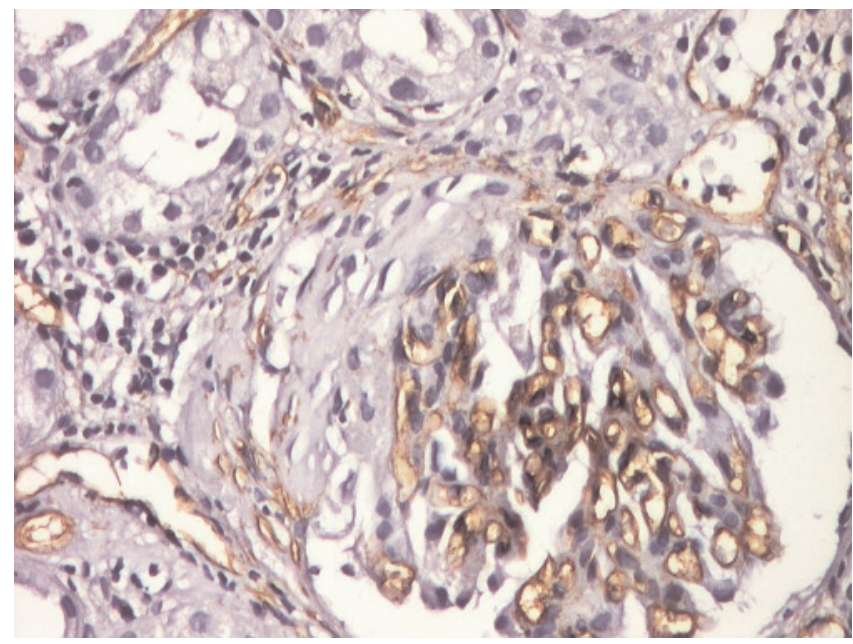

Fig. 1. Glomerulus with adhesions of a capillary loop to the parietal layer of Bowman's capsule. Sclerosed capillary loop with CD34 negative immunoexpression. The remainder of the capillary loops and periglomerular capillaries with CD34 positive immunoexpression. CD34 Stain-LSAB2-DAB (original magnification $\times 200$ ).

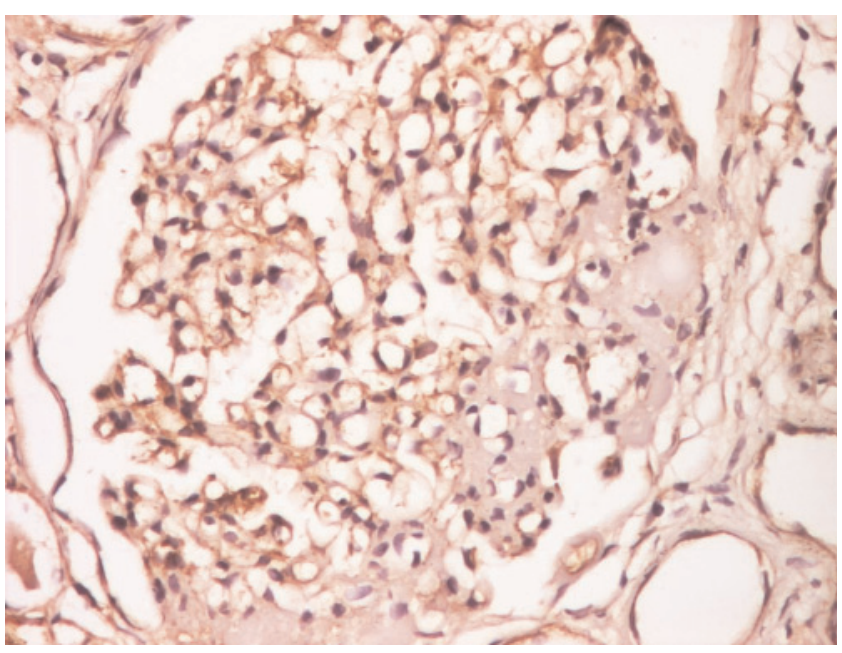

Fig. 3. Glomerulus with non-homogeneous mild to moderate vWF immunoexpression, hyaline nodule with negative vWF immunoexpression. VWF Stain-LSAB-2-DAB (original magnification $\times 200$ ).

of microvascular ECs may be initial and irreversible lesions in progressive nephron loss [22].

It has been well established that even in normal human tissues, expression of EC markers varies among different vascular beds and even among blood capillaries in the same organ [10].

EC marker expression is also modulated under pathological conditions. EC markers can be lost, and this might occur, as mentioned earlier, as a primary or early event.

On the other hand, immunoexpression of the EC markers can increase as an indicator of cell activation or proliferation. It is known that inflammatory

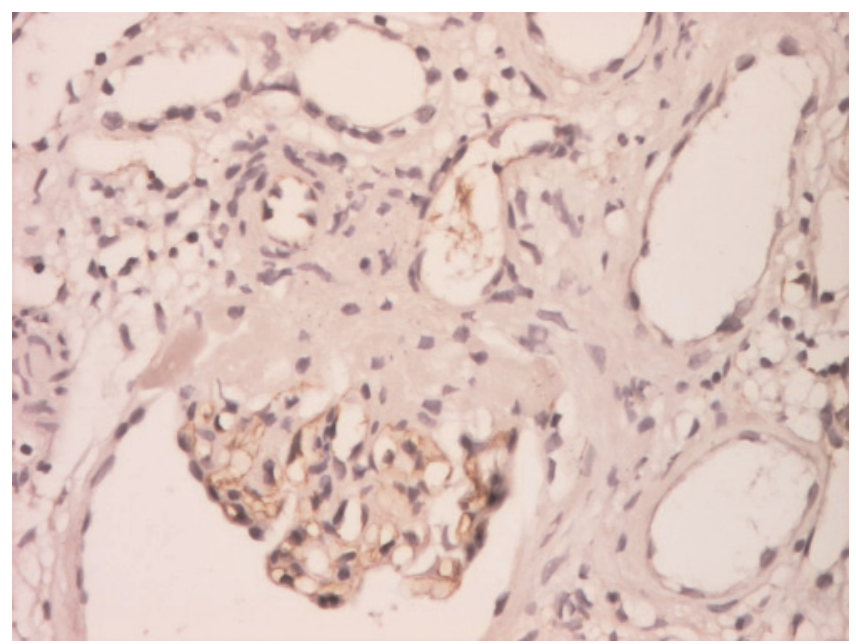

Fig. 2. Glomerulus with adhesions to Bowman's capsule at the level of the vascular pole. CD31 negative immunoexpression at the level of sclerosis and positive CD31 immunoexpression in the capillary loops. CD31 Stain-LSAB-2-DAB (original magnification $\times 200)$.

cytokines can induce an enhanced expression of EC markers by ECs [1].

The immunoexpression of vWF, CD31 and CD34 at the level of the glomerular endothelium and the interstitial vessels was extremely variable in our study.

Patients with crescentic GN showed the highest CD34 immunoexpression (3) at the level of both the glomerular endothelium and the interstitial vessels.

Spearman's rank correlation coefficient did not show any correlation between the immunohistochemical markers and glomerular segmental sclerosis, interstitial fibrosis, AI or CI, which suggests a loss of these markers and microvasculature involvement.

Sclerosing glomeruli were characterized by a striking loss of glomerular capillaries associated with depletion of ECs, similar to the findings of Kang and Lee $[3,19]$.

As mentioned earlier, the three studied markers (vWF, CD31 and CD34) had a non-uniform disposition at the level of the glomerulus. We found that in the glomeruli spared by fibro-sclerotic lesions, the capillaries expressed vWF, CD31 and CD34. In the fibrosclerotic glomeruli, we observed three patterns of immunohistochemical expression of the markers:

- In regions affected by sclerosis, some vessels, although presenting ECs by conventional histology, showed an absence of immunohistochemical markers. This could be explained by the fact that sclerosis at the level of the glomerulus would be preceded by the loss of these markers and could account for a functional deficiency of the ECs, which might lead to sclerosis;

- In some regions of sclerosis, vessels that preserved the immunohistochemical markers were found; and

- In some regions of sclerosis, vessels were absent and so were the markers. 
In regions spared by fibro-sclerotic processes, the immunohistochemical markers were well expressed on the ECs. Furthermore, well defined fibro-sclerotic regions, which sometimes took the shape of nodules, were bordered by uninvolved capillaries with well expressed immunohistochemical markers.

We can summarize that fibro-sclerotic processes at the level of the glomerulus are accompanied by an involvement of the microvasculature. This can be shown either by conventional stains or by immunohistochemistry, which complement one another in studying vessel involvement.

\section{Conclusions}

The immunohistochemical markers vWF, CD31 and CD34 are lost in GN. They no longer correlate with the morphological indices of glomerular sclerosis, interstitial fibrosis, AI and CI. The loss of vWF, CD31 and CD34, most evident in fibrosclerotic lesions, suggests microvasculature involvement. Further studies, in which morphological indices are complemented by immunohistochemical studies, should be carried out given the importance of the microvasculature in the progression of GN.

Acknowledgements: The summary of this paper was presented as a poster at the $40^{\text {th }}$ Annual Meeting of the American Society of Nephrology in San Francisco, U.S.A. October-November 2007

\section{References}

[ 1] Mueller A, Hermanns M, Skrzynski C, Nesslinger M, Mueller K, Kirkpatrick C. Expression of the endothelial markers PECAM-1, vWF and CD34 in vivo and in vitro. Experimental and Molecular Pathology. 2002;72:221-229.

[2] Mutin M, Dignat-George F, Sampol J. Immunologic phenotype of cultured EC: Quantitative analysis of cell surface molecules. Tissue Antigens. 1997;50:449-458.

[ 3] Kang DH, Kanellis J, Hugo C et al. Role of the microvascular endothelium in progressive renal disease. $J$ Am Soc Nephrol. 2002;13:806-816.

[ 4] Olivetti G, Anversa P, Rigamonti W, Vitali-Mazza L, Loud A. Morphometry of the renal corpuscule during normal postnatal growth and compensatory hypertrophy; a light microscopic study. Cell Biol. 1977;75:573-585.

[5] Marcussen N, Nyengaard J, Christensen S. Compensatory growth of glomeruli is accomplished by an increased number of glomerular capillaries. Lab Invest. 1994;70:868-874.

[6] Shimizu A, Kitamura H, Masuda Y, Ishizaki M, Sugisaki Y, Yamanaka N. Rare glomerular capillary regeneration and subsequent capillary regression with endothelial cell apoptosis in progressive glomerulonephritis. Am J Pathol. 1997;151: 1231-1239.

[ 7] Kitamura H, Shimizu A, Masuda Y, Ishizaki M, Sugisaki Y, Yamanaka N. Apoptosis in glomerular endothelial cells during the development of glomerulosclerosis in the remnant kidney model. Exp Nephrol. 1998;6:328-336.

[ 8] Bohle A, Mackensen-Haen S, Wehrmann M. Significance of post-glomerular capillaries in the pathogenesis of chronic renal failure. Kidney Blood Press Res. 1996;19:191-195.
[ 9] Choi YJ, Chakraborty S, Nguyen V et al. Peritubular capillary loss is associated with chronic tubulointerstitial injury in human kidney: Altered expression of vascular endothelial growth factor. Hum Pathol. 2000;31:1491-1497.

[10] Pusztaszeri M, Chaubert P, Seelentag W, Bosman FT. Immunohistochemical expression of endothelial markers CD31, CD34, von Willebrand Factor and FLI-1 in normal human tissues. J Histochem Cytochem. 2006;54:385-395.

[11] Denis CV. Molecular and cellular biology of von Willebrand factor. Int J Hematol 2002;75:3-8.

[12] Sun QH, Paddock C, Visentin GP, Zukowski MM, Muller WA, Newman PJ. Cell surface glycosaminoglycans do not serve as ligands for PECAM-1: PECAM-1 is not a heparinbinding protein. J Biol Chem.1998;273:11483-11490.

[13] Nakada MT, Amin K, Christofidou-Solomidou M et al. Antibodies against the first Ig-like domain of human platelet endothelial cell adhesion molecule-1 (PECAM-1) that inhibit PECAM-1-dependent homophilic adhesion block in vivo neutrophil recruitment. J Immunol. 2000;164:452-462.

[14] Wood HB, May G, Healy L, Enver T, Morriss-Kay GM. CD34 expression patterns during early mouse development are related to modes of blood vessel formation and reveal additional sites of hematopoiesis. Blood. 1997;90:2300-2311.

[15] Neumann I, Kain R, Regele H, Soleiman A, Kandutsch S, Meisl FT. Histological and clinical predictors of early and late renal outcome in ANCA-associated vasculitis. Nephrol Dial Transpl. 2005;20:96-104.

[16] Davison A, Cameron JS, Grunfeld JP et al. Editors. Oxford Textbook of Clinical Nephrology, Third Edition, Oxford University Press; 2005, pp. 169-182.

[17] Dawson B, Trapp RG. Basic and Clinical Biostatistics. Lange; 2004, pp. 48.

[18] Brenner BM, Meyer TW, Hostetter TH. Dietary protein intake and the progressive nature of kidney disease: the role of hemodynamically mediated glomerular injury in the pathogenesis of progressive glomerular sclerosis in aging, renal ablation, and intrinsic renal disease. $N$ Engl $\mathrm{J}$ Med. 1982;307:652-659.

[19] Lee LK, Meyer TW, Pollock AS, Lovett DH. Endothelial cell injury initiates glomerular sclerosis in the rat remnant kidney. J Clin Invest. 1995;96:953-964.

[20] Niemir ZI, Kubiak A, Olejniczak P, Nowak A, Czekalski S. Can von Willebrand factor, platelet- endothelial cell adhesion molecule-1 and thrombomodulin be used as alternative markers of endothelial cell injury in human glomerulonephritis? Rocz Akad Med Bialymst. 2004;49:215-217.

[21] Ohashi R, Kitamura H, Yamanaka N. Peritubular capillary inury during the progression of experimental glomerulonephritis in rats. J Am Soc Nephrol. 2000;11:47-56.

[22] Bottinger EP, Bitzer M. TGF- beta signaling in renal disease. J Am Soc Nephrol. 2002;13:2600-2610.

[23] Adamczak M, Gross ML, Amann K, Ritz E. Reversal of glomerular lesions involves coordinated restructuring of glomerular microvasculature. $J$ Am Soc Nephrol. 2004;15:3063-3072.

[24] Bob FR, Gluhovschi G, Herman D et al. Histological, immunohistochemical and biological data in assessing interstitial fibrosis in patients with chronic glomerulonephritis. Acta Histochem. 2008;110:196-203.

[25] Gluhovschi C, Gluhovschi G, Potencz E et al. What is the significance of CD34 immunostaining in the extraglomerular and intraglomerular mesangium? Virchows Arch. 2008;453: 321-328.

Submitted: 30 June, 2009 Accepted after reviews: 8 February, 2010 